\title{
Time to change the narrative
}

\author{
Habib Benzian, Research Professor, Co-Director WHO Collaborating Centre Quality Improvement \& Evidence-based \\ Dentistry; College of Dentistry, New York University, New York, USA.
}

The BDJ Upfront section includes editorials, letters, news, book reviews and interviews. Please direct your correspondence to the News Editor,

Kate Quinlan atk.quinlan@nature.com. Press releases or articles may be edited, and should include a colour photograph if possible.

$\mathrm{T}$ he narrative of neglect, inequality and lack of political attention in relation to oral health has characterised the advocacy discourse over recent decades. It seemed appropriate to frame global oral health around the gaps, the missing elements, or the glaring unfairness that goes with the massive burden of untreated disease. The political success of such rather negative framing was mixed and notable progress limited, notwithstanding a few outstanding exemptions such as the inclusion of oral health in important global health policy documents of the United Nations. ${ }^{1,2}$ Overall, the narrative of oral health being undervalued, repeatedly overlooked or even deliberately excluded, led to a sort of inferiority complex of the global oral health community. An almost reflexive justification mode in relation to other global health priorities is one of the visible consequences.

This backdrop makes the recent deliberations and decisions at the highest global health levels stand out even more. In January this year, the WHO's Executive Board and, this month, the World Health Assembly adopted resolutions on oral health following a report by the WHO Director-General Dr Tedros Adhanom Ghebreyesus., ${ }^{3,4}$ These decisions have far-reaching implications and consequences for oral health globally, but also for the long-term framing and positioning of oral health in political advocacy and the wider public discourse. ${ }^{5}$

First, the process of developing global policies will guide countries to renew or develop their own national strategies on oral health. This will require extensive consensusbuilding within the oral health arena; but also, with other related communities such as those working to make health systems fit for the challenges of chronic, life-long noncommunicable diseases. The political power of the oral health agenda can only win from this process.
Second, the goal of providing universal access to essential healthcare and preventive services for everyone without financial hardship is at the core of the health-related commitments of the United Nation's Sustainable Development Goals. Making this possible while fully integrating basic oral healthcare services is one of the principal action areas of the decisions taken. The proposed Global Oral Health Strategy, together with a Global Oral Health Action Plan and a monitoring framework to track progress, provide unique and unprecedented opportunities for real change.

\section{'It is now time to add a new narrative to the one of neglect and ignorance.'}

over the coming decade. It is now time to add a new narrative to the one of neglect and ignorance. We need to think about a more positive, forward-looking framing of the challenges and of the opportunities to address them - a narrative of joining hands, of integration, of intersectoral and interprofessional collaboration; and of alignment with the broader context of global health and development. ${ }^{6}$ This change will hopefully contribute to a new perception and self-confidence of the oral health community at large, being equal part of a wider health discourse. The next frontier will be to enable
Third, the mere fact that after long absence, oral health is regaining visibility in the public eye and in the broader global health arena will open doors, foster understanding of the enormous challenges and, eventually, leverage synergies to enable new collaborations and areas of support. There are already promising signs that provide a glimpse on a new future, such as the awakening interest of stakeholders in neglected tropical diseases to include noma in their work, the new Lancet Commission on Oral Health, or even smallish things like encouraging tweets of senior WHO officials related to oral health.

Those old enough to remember the former WHO Global Goals for Oral Health established forty years ago will appreciate the potential impact of even simple global targetsetting for health. The transition from classic tooth-oriented oral epidemiology to metrics that are aligned with global health, health systems performance and measurements for quality and coverage of healthcare will now allow for much more nuanced and innovative monitoring of progress more participation, visibility and voice for people living with oral diseases. This will add an entirely new layer of authenticity and urgency to all efforts to improve oral health, nationally and globally.

\section{References}

1. Wang T T, Mathur M R, Schmidt H. Universal health coverage, oral health, equity and personal responsibility. Bulletin of the WHO 2020; 98: 719-721.

2. Benzian H, Bergman M, Cohen L, Hobdell M, Mackay J. The UN High-level meeting on prevention and control of non-communicable diseases and its significance for oral health worldwide. J Pub Health Dent 2012; 72: 91-93.

3. World Health Organization (WHO). Oral health. Executive Board Resolution EB148/R1 (21 January 2021). Available from https://apps.who.int/gb/ebwha/pdf_files/EB148/ B148_R1-en.pdf (accessed May 2021).

4. WHO Oral Health. Achieving better oral health as part of the universal health coverage and noncommunicable disease agendas towards 2030. Report by the DirectorGeneral (EB148/8) 148th Session of the Executive Board, Provisional Agenda Item 6. 23 December 2020. Available from: https://apps.who.int/gb/ebwha/pdf_files/EB148/ B148_8-en.pdf (accessed May 2021).

5. Benzian $\mathrm{H}$, Beltrán-Aguilar E. The return of oral health to global health is significant for public health everywhere. J Public Health Dent 2021

6. O'Neil M, Sweetland J, Fond M. Unlocking the door to new thinking: Frames for advancing oral health reform. Washington DC: Frameworks Institute, 2017.

https://doi.org/10.1038/s41415-021-3076-y 